Научная статья

УДК $330.15+553.04$

DOI 10.18101/2304-4446-2021-4-42-51

\title{
МИНЕРАЛЬНО-СЫРЬЕВОЙ КОМПЛЕКС В ЭКОНОМИКЕ РЕСПУБЛИКИ БУРЯТИЯ: СОСТОЯНИЕ И ПЕРСПЕКТИВЫ
}

\author{
(C) Дугаржапова Долгорма Баторовна \\ кандидат экономических наук, старший научный сотрудник, \\ Бурятский научный центр Сибирского отделения РАН \\ Россия, 670047, г. Улан-Удэ, ул. Сахьяновой, 8 \\ dolgor@mail.ru
}

\begin{abstract}
Аннотация. В статье представлен анализ основных показателей социальноэкономического развития Республики Бурятия. Выявлены основные причины, обусловливающие низкий уровень развития региональной экономики, качества жизни, сопровождающегося значительной дифференциацией доходов населения. На основе анализа состояния минерально-сырьевой базы отмечена возможность ее использования в качестве приоритетных направлений устойчивого развития республики. Рассмотрены основные показатели, характеризующие влияние минерально-сырьевого комплекса на региональную экономику. Выделены основные факторы, ограничивающие функционирование и развитие минерально-сырьевого комплекса Республики Бурятия. Представлены приоритетные задачи по развитию минерально-сырьевого комплекса республики в рамках эколого ориентированного развития региональной экономики.

Ключевые слова: минеральные ресурсы, месторождения, экономическая дифференциация, региональная экономика, социально-экономическое развитие, устойчивость экономики, депрессивность, депрессивный регион.
\end{abstract}

\section{Для цитирования}

Дугаржапова Д. Б. Минерально-сырьевой комплекс в экономике Республики Бурятия: состояние и перспективы // Вестник Бурятского государственного университета. Экономика и менеджмент. 2021. № 4. С. 42-51.

Введение. Одними из важных задач российской государственной политики является сбалансированное развитие регионов и повышение качества жизни населения во всех субъектах Российской Федерации (РФ) при сохранении их природно-пространственного своеобразия. Реализация поставленных задач осложняется уникальным характером экономической географии России, разнообразием имеющихся материально-природных запасов в регионах, оказывающих непосредственное влияние на диспропорции социально-экономического развития и неравенство доходов населения. В этой связи анализ региональной минерально-сырьевой базы в качестве одного из факторов развития экономики имеет определенный интерес для регионов с неустойчивым социально-экономическим положением.

Социально-экономическое положение Республики Бурятия. Республика Бурятия (РБ) является дотационным регионом. За 2005-2019 гг. расходные средства бюджета превышают доходы, несмотря на значительный рост налоговых доходов (в 4,9 раза) и безвозмездных поступлений (в 5,9 раза) (табл. 1). 
Д. Б. Дугаржапова. Минерально-сырьевой комплекс в экономике Республики Бурятия: состояние и перспективы

Бюджет Республики Бурятия, (млрд руб.)

Таблица 1

\begin{tabular}{|l|c|c|c|c|c|c|}
\hline \multicolumn{1}{|c|}{ Показатели } & 2005 & 2010 & 2015 & 2017 & 2018 & 2019 \\
\hline Доходы & 15,6 & 39,2 & 52,8 & 56,6 & 64,8 & 80,1 \\
\hline $\begin{array}{l}\text { В т. ч.: } \\
\text { налог на прибыль организаций }\end{array}$ & 1,4 & 3,5 & 7,4 & 5,3 & 6,9 & 8,0 \\
\hline налог на доходы физических лии & 3,3 & 8,0 & 11,4 & 12,9 & 14,4 & 15,3 \\
\hline налог на имущество & 1,0 & 1,7 & 4,2 & 4,5 & 5,4 & 5,0 \\
\hline безвозмезднье поступления & 7,3 & 21,2 & 23,8 & 27,1 & 30,7 & 43,0 \\
\hline Расходы & 15,8 & 40,8 & 54,1 & 59,3 & 65,2 & 80,6 \\
\hline $\begin{array}{l}\text { Из них на: } \\
\text { общегосударственнье вопросы }\end{array}$ & 1,4 & 3,7 & 4,0 & 4,4 & 5,1 & 5,3 \\
\hline национальную экономику & 1,1 & 4,8 & 8,0 & 9,6 & 8,6 & 11,4 \\
\hline жилищно-коммунальное хозяйство & 1,2 & 3,0 & 4,0 & 3,4 & 2,9 & 4,1 \\
\hline социально-культурные мероприятия & 11,4 & 25,8 & 36,1 & 40,2 & 45,8 & 57,2 \\
\hline Профицит/дефицит (-) & $-0,3$ & $-1,6$ & $-1,2$ & $-2,7$ & $-0,4$ & $-0,5$ \\
\hline
\end{tabular}

Источник: Регионы России. Социально-экономические показатели. URL: https://rosstat.gov.ru/folder/210/document/13204 (дата обращения: 27.08.2021). Текст: электронный.

Проблемой доходной базы бюджета является отсутствие в регионе крупных компаний-налогоплательщиков. Основная доля поступлений в бюджет осуществляется за счет налогов на доходы физических лиц (НДФЛ). Например, в 2019 г. доля налога на прибыль организаций составила $28,3 \%$ всех доходов, в то время как НДФЛ составил 53,9\%.

В структуре расходов региона преобладает социальная направленность. На финансовое обеспечение социальной политики, образования, здравоохранения, культуры, физкультуры и спорта в течение 2019 г. было направлено 57214,3 млн рублей, что выше аналогичного уровня 2018 г. на $25 \%$.

Одним из индикаторов депрессивного состояния является валовой региональный продукт (ВРП) на душу населения [6]. За 1998-2018 гг. значения данного показателя по Республике Бурятия были значительно ниже, чем по Дальневосточному федеральному округу и по Российской Федерации в целом (табл. 2).

Таблица 2

Валовой региональный продукт на душу населения, тыс. рублей

\begin{tabular}{|c|c|c|c|c|c|c|c|}
\hline Годы & РФ & \multirow{2}{*}{ ДФО } & РБ & \multicolumn{2}{|c|}{ в \% к } & \multicolumn{2}{c|}{ Место } \\
\cline { 5 - 8 } & & & & РФ & ДФО & РФ & ДФО \\
\hline 1998 & 15,37 & 18,06 & 10,95 & 71,26 & 60,66 & 46 & 9 \\
\hline 2005 & 125,66 & 112,96 & 77,31 & 61,53 & 68,44 & 44 & 10 \\
\hline 2010 & 263,83 & 287,69 & 137,56 & 52,14 & 47,82 & 59 & 11 \\
\hline 2015 & 449,10 & 487,85 & 206,88 & 46,07 & 42,41 & 70 & 11 \\
\hline 2016 & 472,05 & 506,92 & 201,62 & 42,71 & 39,77 & 74 & 11 \\
\hline 2017 & 509,38 & 529,94 & 204,83 & 40,21 & 38,65 & 75 & 11 \\
\hline 2018 & 578,74 & 634,21 & 229,84 & 39,71 & 36,24 & 75 & 11 \\
\hline
\end{tabular}

Источник: Регионы России. Социально-экономические показатели. URL: https://rosstat. gov.ru/ folder/210/document/13204 (дата обращения: 27.08.2021). Текст: электронный. 
Данное положение во многом обусловлено значительным падением объемов производства (до 48\% от уровня 1990 г.) в процессе рыночной трансформации экономики и переходных преобразований. Анализ динамики секторов экономики за 2005-2018 гг. свидетельствует о снижении в республике доли первичного сектора экономики на $3,6 \%$, вторичного сектора - на $1,5 \%$ и росте третичного сектора - на 5,1\% (табл. 3).

Структура ВРП в разрезе секторов экономики, \%

Таблица 3

\begin{tabular}{|c|c|c|c|c|c|c|c|c|c|}
\hline $\begin{array}{c}\text { Субъекты } \\
\text { РФ }\end{array}$ & \multicolumn{2}{|c|}{$\begin{array}{c}\text { Сельское хозяй- } \\
\text { ство (первичный } \\
\text { сектор) }\end{array}$} & \multicolumn{2}{|c|}{$\begin{array}{c}\text { Промышленность (вто- } \\
\text { ричный сектор) }\end{array}$} & \multicolumn{3}{|c|}{$\begin{array}{c}\text { Услуги } \\
\text { (третичный сектор) }\end{array}$} \\
\cline { 2 - 10 } & 2005 & 2015 & 2018 & 2005 & 2015 & 2018 & 2005 & 2015 & 2018 \\
\hline $\begin{array}{l}\text { Республика } \\
\text { Бурятия }\end{array}$ & 14,1 & 10,2 & 10,5 & 15,3 & 23,6 & 13,8 & 70,6 & 66,2 & 75,7 \\
\hline
\end{tabular}

Источник: Регионы России. Социально-экономические показатели. URL: https://rosstat.gov.ru/folder/210/document/13204 (дата обращения: 27.08.2021). Текст: электронный.

Сегодня в экономике региона значительна доля отраслей обрабатывающего производства $(12,1 \%)$, торговли $(15,7 \%)$, транспортировки и хранения $(11,4 \%)$ и государственного управления $(10,4 \%)^{1}$.

Немаловажным показателем, напрямую зависящим от развития экономической сферы и характеризующий степень депрессивности региона, является уровень благосостояния населения по доходам [1]. По величине среднедушевых доходов и среднемесячной заработной платы Бурятия занимает последнее место среди регионов ДФО. По доходам регион отстает от средних значений по стране и округу соответственно в 1,4 раза и в 1,5 раза, по заработной плате - в 1,2 и 1,4 раза. За 2005-2019 гг. уровень бедности населения снизился на 12,5\%, тем не менее регион занимает 9-ю позицию в рейтинге субъектов ДФО (табл. 5).

Таблица 5

Индикаторы уровня денежных доходов населения Республики Бурятия

\begin{tabular}{|l|c|c|c|c|c|c|}
\hline \multicolumn{1}{|c|}{ Показатели } & 2005 & 2010 & 2015 & 2017 & 2018 & 2019 \\
\hline $\begin{array}{l}\text { Среднемесячные душевые доходы, } \\
\text { тыс. р. }\end{array}$ & 6,0 & 14,3 & 23,9 & 23,9 & 24,1 & 25,3 \\
\hline $\begin{array}{l}\text { Среднемесячная заработная плата, } \\
\text { тыс. p. }\end{array}$ & 7,7 & 18,0 & 28,4 & 32,2 & 36.0 & 39,1 \\
\hline $\begin{array}{l}\text { Численность населения с доходами } \\
\text { ниже прожиточного уровня, \% }\end{array}$ & 32,6 & 19,2 & 18,9 & 19,0 & 19,1 & 20,1 \\
\hline
\end{tabular}

Источник: Регионы России. Социально-экономические показатели. URL: https://rosstat.gov.ru/folder/210/document/13204 (дата обращения 27.08.2021). Текст: электронный.

1 Регионы России. Социально-экономические показатели. URL: https://rosstat.gov.ru/folder/210/document/13204 (дата обращения: 27.08.2021). Текст: электронный. 
Д. Б. Дугаржапова. Минерально-сырьевой комплекс в экономике Республики Бурятия: состояние и перспективы

Отметим, что наименьшее значение численности населения с доходами ниже прожиточного уровня было достигнуто в 2013 г. За IV квартал 2019 г. величина прожиточного минимума в среднем по региону составила 11274 р., а для трудоспособного населения - 11726 p. ${ }^{1}$ Невысокий уровень жизни сопровождается значительной дифференциацией доходов. 43,6\% всех официальных денежных доходов республики сосредоточены в руках населения с наивысшими доходами. В 2019 г. соотношение 20\% наиболее обеспеченного населения региона и $20 \%$ наименее обеспеченного составило 11,5 раза (в России - 15,6 раза).

Определенную остроту сложившейся ситуации добавляет показатель уровня экономической активности населения Республики Бурятия. Так, в 2019 г. значения данного показателя $(57,4 \%)$ ниже, чем в среднем по стране $(62,3 \%)$ и ДФО $(63,9 \%)$. Для сельской местности этот показатель равен 51,1\%, что на 5,9\% ниже, чем по стране, и на 5,5\% - по округу в целом; для городского населения показатель составил $61,5 \%$ (ниже значений по стране и округу на 3,5 и $4,0 \%$ соответственно). Наибольшая численность занятых наблюдается в отраслях промышленности $(16,0 \%)$, социальной сферы $(17,3 \%)$, торговли и других видов услуг $(43,9 \%)$. Уровень безработицы $(9,2 \%)$ в регионе в 2 раза выше к среднему по России и в 1,5 раза по ДФО. Из всех безработных 25,9\% имеют высшее образование, $37,6 \%$ среднее профессиональное образование и $36,6 \%$ образование ниже среднеобщего. Доля безработной молодежи (20-29 лет) в республике несколько ниже, чем в среднем по ДФО (27,6\% в РБ, 33,0\% в ДФО), однако доля безработных в возрасте 30-39 лет значительно выше (30\% в РБ, в ДФО - 25,6\%)

Данные показатели свидетельствуют о наличии проблем конкурентоспособности рабочей силы, несоответствии спроса и предложения на рынке труда, что обусловливает социальную напряженность среди населения и углубляет депрессивное состояние экономики региона.

Минерально-сырьевая база Республики Бурятия. Бурятия занимает одно из ведущих мест по минерально-сырьевым запасам в России. В регионе содержится 95,9\% российских запасов таллия, $52 \%$ цинка, $44,6 \%$ вулканического стекла, $35 \%$ кадмия, $32,3 \%$ молибдена, $24,4 \%$ свинца и пр. [2; 4; 5; 9-11]. Более 20 видов минерального сырья республики входят в перечень стратегически важных $^{3}$. В целом на территории республики расположено свыше 700 месторождений полезных ископаемых, из которых 600 поставлено на государственный баланс стоимостью, превышающей 210 млрд долл. ${ }^{4}$

\footnotetext{
${ }^{1}$ Величина прожиточного минимума в целом по России и по субъектам Российской Федерации. URL: https://rosstat.gov.ru/folder/13723 (дата обращения: 27.08.2021). Текст: электронный.

2 Регионы России. Социально-экономические показатели. URL: https://rosstat.gov.ru/ folder/210/document/13204 (дата обращения: 27.08.2021). Текст: электронный.

${ }^{3} \mathrm{O}$ перечне основных видов стратегического минерального сырья: распоряжение Правительства РФ № 50-p. Утв. 16.01.1996 г. // Техэксперт. URL: http://docs.cntd.ru/ document/9015641 (дата обращения: 28.08.2021). Текст: электронный.

${ }^{4}$ O состоянии и охране окружающей среды Республики Бурятия в 2020 году: государственный доклад Министерства природных ресурсов и экологии Республики Бурятия. URL: https://economy.govrb.ru/mpr/activities/reports_and_reports/gosudarstvennyy-doklad.php (дата обращения: 31.08.2021). Текст: электронный.
} 
В 2019 г. в отраслевой структуре валовой добавленной стоимости региона добыча полезных ископаемых характеризуется незначительной долей $-5,1 \%$ (для сравнения РФ - 13,5\%, ДФО - 28,7\%) ${ }^{1}$. Вместе с тем налоги на добычу полезных ископаемых в бюджетную систему РФ по виду экономической деятельности «Добыча полезных ископаемых» от республики составили 1,4 млрд p. $^{2}$ Следовательно, эффективное освоение и использование многообразия минеральносырьевых ресурсов региона способствуют их рассмотрению в качестве одного из важнейших факторов устойчивого развития республики [3].

Анализ основных показателей добывающей промышленности Республики Бурятия за последние 5 лет свидетельствует о его достаточно стабильном развитии (табл. 6).

Таблица 6

Основные индикаторы добывающей промышленности

Республики Бурятия за 2016-2020 гг.

\begin{tabular}{|l|c|c|c|c|c|}
\hline \multicolumn{1}{|c|}{ Показатель } & 2016 & 2017 & 2018 & 2019 & $2020^{*}$ \\
\hline Число действующих организаций & 328 & 321 & 338 & 394 & 410 \\
\hline $\begin{array}{l}\text { Объем отгруженных товаров в фактически дей- } \\
\text { ствовавших ценах), млрд руб. }\end{array}$ & 22,5 & 25,3 & 28,0 & 36,8 & 46,3 \\
\hline $\begin{array}{l}\text { В том числе: } \\
\text { добыча угля }\end{array}$ & 2,7 & 6,9 & 9,9 & 15,1 & 21,9 \\
\hline добыча металлических руд & 18,5 & 16,6 & 16,2 & 19,0 & 22,8 \\
\hline добыча прочих полезных ископаемых & 1,2 & 1,8 & 1,9 & 2,7 & 1,5 \\
\hline Индекс производства, в \% к предыдущему году & 101,3 & 106,9 & 108,6 & 127,0 & 115,7 \\
\hline В т. ч. & & & & & \\
\hline добыча угля & 156,5 & 144,9 & 144,9 & 161,0 & $\ldots$ \\
\hline добыча металлических руд & 97,3 & 96,7 & 100,5 & 100,2 & $\ldots$ \\
\hline добыча прочих полезных ископаемых & 88,9 & 134,6 & 95,8 & 214,0 & 79,4 \\
\hline Среднесписочная численность, тыс. человек & $\ldots$ & $\ldots$ & 6,2 & 5,8 & 5,8 \\
\hline Сальдо финансового результата, млрд руб. & 9,8 & 9,8 & 12,8 & 5,9 & 2,9 \\
\hline Рентабельность продукции, \% & 24,5 & 21,8 & 28,6 & 14,6 & 12,7 \\
\hline Среднемесячная заработная плата, тыс. руб. & 55,5 & 65,7 & 69,8 & 77,4 & 86,8 \\
\hline $\begin{array}{l}\text { В том числе: } \\
\text { добыча угля }\end{array}$ & $\ldots$ & 40,8 & 66,6 & 73,1 & 74,1 \\
\hline добыча металлических руд & $\ldots$ & 71,6 & 74,8 & 84,2 & 96,3 \\
\hline добыча прочих полезныхх ископаемых & $\ldots$ & 35,0 & 37,9 & 45,8 & 65,8 \\
\hline
\end{tabular}

Источник: Бурятия в цифрах (статистический сборник 01-01-13) [Электронный реcypc]. URL: https://burstat.gks.ru/prom (дата обращения: 30.08.2021).

\footnotetext{
${ }^{1}$ Отраслевая структура валовой добавленной стоимости субъектов Российской Федерации 2016-2019 гг. URL: https://rosstat.gov.ru/accounts (дата обращения: 27.08.2021). Текст: электронный.

${ }^{2}$ Отчет о поступлении налогов, сборов и страховых взносов в бюджетную систему Российской Федерации по основным видам экономической деятельности по состоянию на 01.01.2020 г. URL: https://www.nalog.gov.ru/rn77/related_activities/statistics_and_analytics/ forms/9690014/. (дата обращения: 27.08.2021). Текст: электронный.
} 
Д. Б. Дугаржапова. Минерально-сырьевой комплекс в экономике Республики Бурятия: состояние и перспективы

В 2020 г. в МСК республики число действующих предприятий увеличилось в 1,25 раза по сравнению с прошлым годом. За последние три года среднесписочная численность работников в отрасли добычи полезных ископаемых снизилась на $6,8 \%$. Одной из причин является переход предприятий на аутсорсинг и перевод работников в подрядные организации. Среднемесячная заработная плата в добывающей промышленности является самой высокой в республике и более чем в 3,5 раза превышает самую низкую оплату труда, наблюдаемую в сфере гостиниц и предприятий общественного питания $(21933,4$ р.) и в 2,1 раза выше среднего значения по региону $(41800,1 \text { р. })^{1}$. Объем отгруженной продукции в добыче полезных ископаемых увеличился на $25,8 \%$ по сравнению с прошлым годом и составил $27,4 \%$ объема промышленного производства в целом по республике 2 . Наибольшее увеличение произошло в добыче угля (в 1,4 раза), в добыче металлических руд - в 1,2 раза.

Вместе с тем за анализируемый период в добывающей отрасли региона наблюдается снижение рентабельности продажи продукции (в 1,9 раза) из-за падения прибыли (в 3,4 раза). Негативные процессы, отрицательно влияющие в условиях действующей рыночной ситуации на финансовое состояние организаций добывающей промышленности и их финансовую безопасность, определяются многочисленными факторами. В их числе труднодоступность, устаревшие технологии извлечения сырья, ошибки в разработке освоения месторождений, разведка, строительство инфраструктуры, промышленная разработка, рекультивация.

Тормозящим фактором развития добывающей промышленности является и высокая степень износа основных фондов. За 2016-2019 гг. в республике наблюдается снижение ввода в действие основных фондов (в 4,1 раза) на фоне роста их износа и уничтожения (табл. 7).

Таблица 7

Основные показатели состояния и структуры основных фондов добывающей промышленности Республики Бурятия

\begin{tabular}{|l|c|c|c|c|}
\hline \multicolumn{1}{|c|}{ Показатель } & 2016 & 2017 & 2018 & 2019 \\
\hline Основные фонды, млрд руб. & 36,2 & 41,7 & 45,0 & 40,7 \\
\hline $\begin{array}{l}\text { Из них (в \%): } \\
\text { зданий }\end{array}$ & 10,0 & 10,6 & 11,2 & 11,3 \\
\hline сооружений & 30,6 & 36,7 & 41,3 & 37,8 \\
\hline машин и оборудований & 40,3 & 39,5 & 34,7 & 37,3 \\
\hline транспортных средств & 12,4 & 12,1 & 12,0 & 12,7 \\
\hline прочие & 6,7 & 1,1 & 0,8 & 1,0 \\
\hline Степень износа, \% & 38,4 & 39,4 & 41,9 & 39,9 \\
\hline Удельный вес полностью изношенных основных фондов, \% & 9,8 & 14,4 & 16,0 & 12,3 \\
\hline Ввод в действие основных фондов, млрд руб. & 11,3 & 7,8 & 3,8 & 2,8 \\
\hline Ликвидация основных фондов, млн руб. & 108,0 & 23,2 & 66,5 & 137,6 \\
\hline
\end{tabular}

Источник: Статистический ежегодник. URL: https://burstat.gks.ru/bur_compendium (дата обращения: 30.08.2021). Текст: электронный.

${ }^{1}$ Статистический ежегодник. URL: https://burstat.gks.ru/bur_compendium (дата обращения: 30.08.2021). Текст: электронный.

2 Бурятия в цифрах (статистический сборник 01-01-13). URL: https://burstat.gks.ru/prom (дата обращения: 30.08.2021). Текст: электронный. 
Данные таблицы 7 свидетельствуют о высокой доле морально и физически устаревших основных фондов, что отрицательно отражается на показателях деятельности предприятий. Требуется техническое перевооружение добывающих организаций с целью роста уровня эффективности их деятельности, прироста прибыльности и рентабельности.

В свою очередь, увеличение собственного капитала способствует росту геологоразведочных работ, тем самым расширяя деятельность добывающих предприятий. Так, например, в 2020 г. финансирование геологоразведочных работ (ГРР) за счет собственных средств в 5,6 раза превысило средства федерального бюджета (табл. 8).

Таблица 8

Финансирование геологоразведочных работ в 2020 г., млн руб.

\begin{tabular}{|l|c|c|}
\hline \multicolumn{1}{|c|}{ Виды ресурсов } & $\begin{array}{c}\text { Средства федерального } \\
\text { бюджета }\end{array}$ & $\begin{array}{c}\text { Собственные средства } \\
\text { предприятий }\end{array}$ \\
\hline Всего: & 457 & 2565,4 \\
\hline $\begin{array}{l}\text { В т. ч.: } \\
\text { уран }\end{array}$ & 123,2 & 0,0 \\
\hline уголь & 0,0 & 8,4 \\
\hline $\begin{array}{l}\text { черные, цветные, редкие } \\
\text { металлы }\end{array}$ & 0,0 & 28,4 \\
\hline золото & 109,3 & 1804,3 \\
\hline неметаллы & 0,0 & 719,6 \\
\hline воды подземные & 0,0 & 4,7 \\
\hline
\end{tabular}

Источник: Статистический ежегодник. URL: https://burstat.gks.ru/bur_compendium (дата обращения 30.08.2021). Текст: электронный.

По результатам работ прирост запасов магматической породы (строительный камень) составил 8 210,1 тыс. м³ доломитов - 3,09 тыс. ${ }^{3}{ }^{1}$. Следует отметить, что в Бурятии начиная с 1960-х гг. при разведке основных месторождений практически не изучались запасы попутных редких и редкоземельных металлов. В настоящее время для большинства месторождений республики отсутствует экономическая оценка [10]. Таким образом, возможности увеличения геологоразведочных работ способствуют не только обеспечению горнодобывающих предприятий разведанными запасами полезных ископаемых, но и более эффективному их освоению с учетом охраны окружающей среды и экономически оправданных объемов производства.

Заключение. Республика Бурятия обладает минерально-сырьевой базой, позволяющей поддерживать промышленный потенциал региона и экспортировать ряд стратегических видов минерального сырья как в зарубежные страны, так и в другие регионы России. В то же время добывающая промышленность региона не обеспечивает доходы регионального бюджета в должной мере.

${ }^{1} \mathrm{O}$ состоянии и охране окружающей среды Республики Бурятия в 2020 году: государственный доклад Министерства природных ресурсов и экологии Республики Бурятия. URL: https://economy.govrb.ru/mpr/activities/reports_and_reports/gosudarstvennyy-doklad.php (дата обращения 31.08.2021). Текст: электронный. 
Д. Б. Дугаржапова. Минерально-сырьевой комплекс в экономике Республики Бурятия: состояние и перспективы

В числе основных факторов, ограничивающих деятельность горнодобывающих предприятий, можно выделить слабую изученность минерально-сырьевого потенциала, изучение совершенствования мер экономического стимулирования геологического изучения недр, низкий процент освоения месторождений; необходимость обогащения запасов по рентабельным видам полезных ископаемых, недостаточность финансирования инновационно-технологического развития добывающих предприятий и другое.

Ситуацию также усложняют экологические ограничения, действующие в отношении Байкальской природной территории, согласно которым в центральной экологической зоне БПТ запрещаются разведка и разработка новых месторождений полезных ископаемых, ранее не затронутых эксплуатационными работами, добыча минеральных и термальных вод, добыча сырой нефти и природного газа, радиоактивных и металлических руд, добыча полезных ископаемых на озере Байкал, в его водоохранной зоне, в руслах нерестовых рек и их водоохранных зонах, кроме добычи подземных вод для целей питьевого и хозяйственнобытового водоснабжения, минеральных и термальных вод ${ }^{1}$.

С учетом выделенных региональных факторов и проблем, сложившихся в целом в отечественном минералопользовании, республиканскими органами власти к приоритетным задачам по развитию минерально-сырьевого комплекса Республики Бурятия отнесены: 1) количественное наращивание минерально-сырьевой базы за счет увеличения инвестиционной привлекательности ГРР всех стадий, повышения эффективности прогнозирования и поисков новых месторождений; 2) рациональное использование уже имеющейся минерально-сырьевой базы за счет использования современных технологий переработки, обогащения и комплексного извлечения полезных ископаемых на известных неразрабатываемых месторождениях, повышения качества и глубины переработки минерального сырья ${ }^{2}$.

Результатом решения задач является увеличение доли добычи полезных ископаемых в промышленности республики, создание новых рабочих мест, увеличение налоговых поступлений от организаций отрасли в бюджетную систему РФ, что в целом способствует устойчивому социально-экономическому развитию региона.

\section{Литература}

1. Архипова М. Ю., Сиротин В. П. Подходы к изучению качества и уровня жизни населения в России // Вестник РФФИ. Гуманитарные и общественные науки. 2020. № 4. C. 34-44. DOI: $10.22204 / 2587-8956-2020-101-04-34-44$

\footnotetext{
${ }^{1}$ Об утверждении перечня видов деятельности, запрещенных в центральной экологической зоне Байкальской природной территории: постановление Правительства РФ от 31 декабря 2020 г. № 2399. URL: https://www.garant.ru/products/ipo/prime/doc/400067820/ (дата обращения: 30.09.2021). Текст: электронный.

${ }^{2}$ О государственной программе Республики Бурятия «Охрана окружающей среды и рациональное использование природных ресурсов»: постановление Правительства Республики Бурятия от 30 мая 2013 г. № 261 (с изменениями на 20 мая 2021 года). URL: https://docs.cntd.ru/document/473805591 (дата обращения 30.09.2021). Текст: электронный.
} 
2. Бахтин В. И., Яловик Г. А. Состояние и перспективы развития минеральносырьевой базы Республики Бурятия до 2020 г. // Разведка и охрана недр. 2007. № 12. C. $6-15$.

3. Гордиенко И. В. Ресурсы стратегического минерального сырья Республики Бурятия: состояние и перспективы развития // Науки о Земле и недропользование. 2020. Т. 43, № 1. C. 8-35. DOI: https://doi.org/10.21285/2686-9993-2020-43-1-8-35

4. Гордиенко И. В., Булгатов А. Н., Орсоев Д. А. Геодинамические обстановки и металлогения Саяно-Байкальской горной области // Отечественная геология. 2013. № 3. С. 7-15.

5. Дондоков 3. Б.-Д., Потапов Л. В., Кислов Е. В. Основные направления и проблемы развития минерально-сырьевого сектора Республики Бурятия // География и природные ресурсы. 2019. № 1. С. 137-145.

6. Карпунина Е. К., Колесниченко Е. А. Валовой региональный продукт как основной показатель развития региона // Социально-экономические явления и процессы. 2008. № 1(009). С. 35-41.

7. Киммельман С. А. Новая экономическая модель развития минерально-сырьевой и промышленно-перерабатывающей отраслей (предложения в решение Экспертной группы №1 по обновлению «Стратегии - 2020»). URL: http://strategy2020.rian.ru/g8/ (дата обращения: 31.08.2021). Текст: электронный.

8. Минерально-сырьевой сектор Азиатской России: как обеспечить социальноэкономическую отдачу / под редакцией В. В. Кулешова. Новосибирск: ИЭОПП СО РАН, 2015. $352 \mathrm{c}$.

9. Богатство недр России: минерально-сырьевой и стоимостной анализ / Б. К. Михайлов, О. В. Петров, С. А. Кимельман [и др.]. Санкт-Петербург: Изд-во ВСЕГЕИ, 2008. $484 \mathrm{c}$.

10. Таханова С. С. Управление недрами Республики Бурятия // Разведка и охрана недр. 2017. № 9. С. 3-10.

11. Яловик Г. А. Состояние и перспективы развития минерально-сырьевой базы Республики Бурятия до 2020 года // Глобус: геология и бизнес. 2010 . № 5 (13). С. 14-29.

Статья поступила в редакцию 05.10.2021; одобрена после рецензирования 29.10.2021; принята к публикации 01.11.2021.

\section{MINERAL RESOURCES SECTOR IN THE ECONOMY OF THE REPUBLIC OF BURYATIA: CURRENT STATE AND TRENDS}

Dolgorma B. Dugarzhapova

Cand. Sci. (Econ.), Senior Researcher,

Buryat Scientific Center SB RAS

8 Sakhyanovoy St., Ulan-Ude 670047, Russia

dolgor@mail.ru

Abstract. The article presents an analysis of the main indicators of the socio-economic development of the Republic of Buryatia. We have identified the main reasons for the underdevelopment of the regional economy, the quality of living, and the significant differentiation of personal incomes. An analysis of the state of raw material base shows the possibility of its use as a priority area of the republic's sustainable development. We have considered the key indicators characterizing the influence of the mineral resource sector on the regional economy, and revealed the main factors limiting the functioning and development of the mineral resource sector in the Republic of Buryatia. The article presents the priority tasks 
Д. Б. Дугаржапова. Минерально-сырьевой комплекс в экономике Республики Бурятия: состояние и перспективы

for the development of the mineral resource sector in the republic within the framework of the environmentally friendly economy.

Keywords: mineral resources, mineral assets, economic differentiation, regional economy, socio-economic development, economic resilience, depressiveness, depressed region.

\section{For citation}

Dugarzhapova D. B. Mineral Resources Sector in the Economy of the Republic of Buryatiya: Current State and Trends. Bulletin of Buryat State University. Economy and Management. 2021; 4: 42-51 (In Russ.).

The article was submitted 05.10.2021; approved after reviewing 29.10.2021; accepted for publication 01.11.2021. 